\title{
Original Article-II
}

\section{Clinical and Radiological Features of Paediatric Burkitt's Lymphoma - A Four Year Study.}

\author{
BOSCO J I E, APPAJI L, ARUNA K, RAGHURAM P, RAMA RAO C, VIDHYA A
}

\begin{abstract}
Background: Burkitt's lymphoma is a curable childhood malignancy with significant geographical variation in incidence, clinical presentation and response to treatment. There is sparse literature on Burkitt's lymphoma from India.
\end{abstract}

Methods: Between 2003 and 2007, 19 cases of Burkitt's lymphoma were diagnosed at our centre. Their clinical presentation and radiological features were studied.

Results: The mean age was 7.2 years (range1 to 5 years). There was a slight male preponderance $(M: F=1.7: 1)$. Almost all the cases were seen over a 2 to 3 month period. The most common presentation was an abdominal mass followed by a maxillarymandibular swelling. The most common imaging finding was a lobulated, hypermixed echogenic abdominal mass on ultrasonography and a hypodense, heterogeneously enhancing intra-abdominal mass with necrotic foci on CAT scan. Most of the cases $(84.2 \%)$, were stage III (St. Judes staging) at the time of presentation. Fourteen of 19 cases received treatment of which 10 (71.4\%) achieved remission.

Conclusion: Our cases show an intermediate pattern - having clinical characteristic of both the African and the American forms of Burkitt's lymphoma.

Department of Pediatric Oncology, Kidwai Memorial Institute of

Oncology, Bangalore

Corresponding author: JEROME I E BOSCO

Email : dr_vidhyajerome@rediffmail.com

\section{INTRODUCTION}

Burkitt's lymphoma (BL), a high grade B cell neoplasm showing monoclonal proliferation, was first described in 1957, by an Irish surgeonDenis Parsons Burkitt who mapped its peculiar geographic distribution across equatorial Africa. Its etiological factors include the Epstein Barr virus - the first reported oncogenic virus in humans ${ }^{1}$. Prospective studies in Uganda ${ }^{2}$ have confirmed its role. In 1982 the C-myc gene ${ }^{3}$ was reported and abnormal production of $B$ lymphocytes was noted in translocation between long arms of chromosome 8 with 14 and, to a lesser extent between chromosomes 8, 22 and 2, 8. Other complicating factors include falciparum malarial infection which acts by an EBV specific $\mathrm{T}$ cell immune deficiency. Radiology plays a vital role in staging the disease ${ }^{4}$ and further management as clinical and pathological examination alone cannot decide the extent of disease - patients with a primary in head and neck region may have clinically non-detectable disease in abdomen ${ }^{5}$ - necessitating abdominal imaging in all cases of BL. As BL is a fast growing tumour, its earlier detection and treatment decides the outcome. Also response to treatment can be correlated to decrease in size of mass, and best evaluated by imaging studies.

Two distinct types of BL are known (i) the African or endemic form seen in equatorial Africa and Papua New Guinea - here this is the commonest childhood malignancy (100 per million), classically associated with EBV infection (upto $100 \%$ ), seen in malarial endemic areas, commonly involves the jaw, affects younger individuals with mean age of 7 years, and shows good response to 
chemotherapy (ii) American or sporadic form is uncommon (1 per million ), evidence of EBV infection is seen in $20 \%$ of cases, median age is relatively higher and there is male preponderance and poor response to chemotherapy.

There have been reports of $\mathrm{BL}$ occurring in case clusters for place and time, ${ }^{7,8}$ the exact cause of which is only speculative. It has been attributed to endemic malaria in regions which in turn varies with climate, especially rainy season.

Even though disease has been characterized in endemic and nonendemic areas, little information is available from India. The present study tries to look for the type of presentation, radiological features, and clustering of BL in a oncology referral centre from South India.

\section{PATIENTS AND METHODS}

This cross sectional study was conducted in the department of Pediatric Oncology and Department of Radiodiagnosis, Kidwai Memorial Institute of Oncology, Bangalore.

All patients of BL underwent complete evaluation and diagnosis was confirmed by histomorphology, immunohistochemistry, cytology and karyotyping, from 2003 onwards. Bone marrow aspiration and CSF cytology was done to stage the disease. The time of presentation was an interesting finding, with cases presenting in clusters - in the year 2003, all the 5 cases of BL presented between July and September, and in the year 2006-07 - 7 out of the 8 cases, presented between October and January. St. Jude's Children Research Hospital Staging system was used for staging. ${ }^{9}$ Radiological findings- including chest radiograph, OPG, ultrasonography, CT and MRI were tabulated. The treatment course was charted for all patients. Parental consent was taken, if any patient was photographed.

\section{Results (table1 \& 2 )}

A total of 1600 cases of childhood malignancies were seen in the year 2003 to 2006 with an average of 400 per year, $12.4 \%$ of these were lymphomas (both Hodgkin's and non Hodgkin's). BL comprised $9.1 \%$ of all lymphomas and $23.7 \%$ of the Non Hodgkin's lymphomas in a year. Of the 19 patients-12 were diagnosed with cytology and karyotyping and 7 by biopsy and immunohistochemistry.

A total of 19 children were studied with ages from 1 to 15 years - mean age of $7.2( \pm-3.9)$ years, shown in table 1 . There was a slight male predominance -12 boys to 7 girls $(\mathrm{M}: \mathrm{F}=1.7: 1)$, (table 2).

The most common clinical finding was an abdominal mass - seen in 14 individuals (73.7\%), cervical, inguinal lymphadenopathy in 9 children (47.4\%), maxillary-mandibular swelling - in 6 cases (31.6\%). Others included hepatosplenomegaly, ascites, proptosis, swelling in frontal region, and pallor.

Imaging: The most common findings were lobulated hyper-mixed echogenic mass in the abdomen on USG, or hypodense, heterogeneously enhancing intraperitoneal mass with areas of necrosis on CT scan (fig1)- often encasing mesenteric vessels and bowel - seen in $14(73.7 \%)$ patients. Of the abdominal masses 9 showed more than one site of involvement - 13 involved small/large bowel and adjacent mesentery, 9 occurred in the retroperitoneum paraaortic regions, 2 presented in the ileo-caecal region, and 2 in the uterus / adnexal region. Other intra-abdominal findings included renal mass in 2, hepatomegaly-4, splenomegaly 3 , adrenal mass in 1 and ascites in 2 patients. The extra-abdominal findings included maxillary

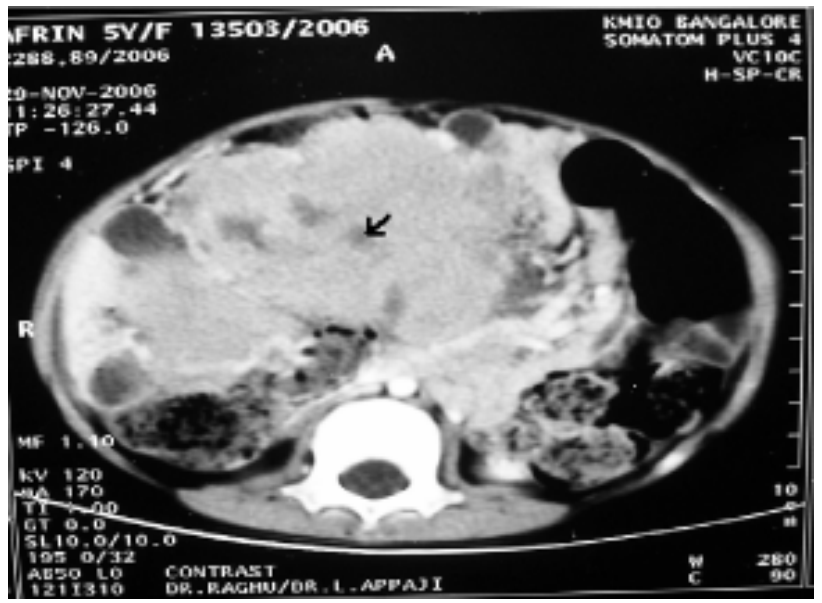

FIGURE 1. CECT of a case of abdominal Burkitt's lymphoma in a child. 
Table 1: Patient's Characteristics

\begin{tabular}{|l|l|l|}
\hline Total no of patients & 19 & \\
\hline Age & 7.2 years & (range=1-15 ) \\
\hline Sex= Male:female & $12: 7$ & \\
\hline Clinical findings & Number of patients & PERCENTAGE \\
\hline 1)Abdominal mass & 14 & 73.7 \\
\hline 2)Cervical / inguinal lymphadenopathy & 9 & 47.4 \\
\hline 3)Maxillary-mandibular swelling & 5 & 26.3 \\
\hline 4)Hepatomegaly & 4 & 21 \\
\hline 5)Splenomegaly & 3 & 15.8 \\
\hline 6)Ascites & 2 & 10.5 \\
\hline 7)Proptosis & 1 & 5.3 \\
\hline 8)Frontal swelling & 1 & 3.3 \\
\hline 9)Pallor & 6 & 31.6 \\
\hline Diagnosis & & \\
\hline Biopsy+Immunohistochemistry & 7 & \\
\hline Cytology+karyotyping & 12 & \\
\hline Staging & & \\
\hline I & 1 & \\
\hline IIE & 1 & \\
\hline III & 16 & \\
\hline IV & & \\
\hline
\end{tabular}

Table 2: Radiological Findings in Burkitt's lymphoma $(n=19)$

\begin{tabular}{|l|c|l|}
\hline RADIOLOGICAL FINDING & Number of patients & PERCENTAGE \\
\hline Mass involving / encasing - bowel / mesentery & 14 & 73.7 \\
\hline Intra / retroperitoneal lymphadenopathy & 9 & 47.4 \\
\hline Maxillary swelling & 4 & 21 \\
\hline Hepatomegaly & 4 & 21 \\
\hline Splenomegaly & 3 & 15.8 \\
\hline Renal mass & 2 & 10.5 \\
\hline Uterine / adnexal mass & 2 & 10.5 \\
\hline Mediastinal / hilar mass & 2 & 10.5 \\
\hline Bonelesion & 2 & 10.5 \\
\hline Ascites & 2 & 10.5 \\
\hline Mandibular swelling & 1 & 5.3 \\
\hline Testicular mass & 1 & 5.3 \\
\hline Adrenal mass & 1 & 5.3 \\
\hline
\end{tabular}


region mass in 4, mandibular - 1 , frontal region - which turned out to be cutaneous BL, hilar / mediastinal mass in 2 , and the rare primary bone involvement in 2 .

Staging: 16 of 19 children had stage 3, remaining 3 cases had IE (1-cutaneous BL), IIE (1-primary bone involvement) and stageIV (1bone marrow and CSF positivity) disease. 14 (73.7\%) of 19 children received chemotherapy - either COMP (Cyclophosphamide, Vincristine, Methotrexate and Prednisone) or MCP842 (Cyclophosphamide, high dose Cytosine arabinoside, Vincristine, Doxorubicin, Ifofsamide, Etoposide, and Methotrexate) protocols, with 10 out of $14(71.4 \%)$ showing disease remission. 4 patients died -2 due to progressive disease, 1 in early relapse, and another due to infection during induction.

\section{DISCUSSION}

The cases of BL which presented to our Institute represent the case load in Karnataka state, South India, from where majority of our patients came.

The most interesting finding we had was the case clustering in time - in 2003 all the 5 cases of BL presented between 2 months - July to September, and in year 2006-07 - 7 out of the 8 cases presented in a 3 month period - October to January. Reason for such a seasonal variation is not clear. Clustering in time and place for $\mathrm{BL}$ has been described previously in Africa $^{7}$ and America. ${ }^{8}$

Clinical presentation in our series was of intermediate i.e between endemic (African) and sporadic (American) type. Maxillary or mandibular swelling $(26.3 \%)$, proptosis $(5.3 \%)$, frontal swelling $(3.3 \%)$ would represent endemic variety and abdominal mass seen in $73.7 \%$ of children was like sporadic variety.

On radiological imaging - the most common finding ( $73.7 \%$ ) was a lobulated hyper - mixed echogenic intra-abdominal mass on USG and a hypodense, heterogeneously enhancing mass with areas of necrosis, encasing mesenteric vessels, bowel on CT. Modern chemotherapy and multidrug treatment over 6 months have improved the prognosis for BL. In present study 10 of 14 children achieved complete remission.
Conclusion: Burkitt's lymphoma is a high grade $\mathrm{B}$ cell neoplasm which is curable with intensive chemotherapy. Early diagnosis defines the treatment outcome, radiology thus plays an important role. Our findings suggest that Burkitt's lymphoma must be suspected strongly in a child presenting with large lobulated intraabdominal mass and histological diagnosis must be established as soon as possible.

Our study population suggested an intermediate form of $\mathrm{BL}$ showing features characteristic of both the African or endemic and the American or sporadic forms. Further clustering of cases and clinical variety were interesting observations in our study.

\section{REFERENCES:}

1. Pagano JS. Epstein-Barr virus: the first human tumour virus and its role in cancer. University of North Carolina at Chapel Hill, Lineberger Comprehensive Cancer Center 27599-7295, USA.

2. Geser A, de The G, Lenoir G, et al. Burkitt's Final case reporting from the Ugandan prospective study of the relationship between $E B V$ and lymphoma. Int $J$ Cancer.1982;29(4):397-400.

3. Gerbitz A, Mautner J, Geltinger C, et al. Deregulation of the proto-oncogene $c$-myc through $t(8 ; 22)$ translocation in Burkitt's lymphoma. Oncogene. 1999;18:1745-1753.

4. Hupp JR, Collins FJ, Ross A, et al. A review of Burkitt's lymphoma. Importance of radiographic diagnosis. J Maxillofac Surg. 1982;10(4):240-5.

5. Aywak AA, Mwanda OW, Adamali NE. Radiological features of Burkitt's lymphoma.East Afr Med J. 2004; (8 Suppl):S104-10.

6. Gutierrez MI, Bhatia K, Barriga F, et al. Molecular epidemiology of Burkitt's lymphoma from South America: differences in breakpoint location and Epstein-Barr virus association from tumours in other world regions. Blood.1992;79(12):3261-6

7. Williams EH, Smith PG, Day NE, et al. Space-time clustering of Burkitt's lymphoma in the West Nile district of Uganda: 1961-1975. Br $J$ Cancer. 1978;37(1):109-22.

8. Heath $C W J$. Investigating causation in cancer clusters. Radiation and Environmental Biophysics 1996;35:133-6.

9. Howard JW, Nancy JT.Lymphomas. In: Cancer Principles and Practice of Oncology, $7^{\text {th }}$ edn. Eds Vincent TD Jr, Samuel H, Steven AR. Philadelphia, Lippincott Williams \& Wilkins 2005;pp1950. 